\section{Anxiety symptoms in clinically diagnosed bruxers}

Manfredini D, Landi N etal. J Oral Rehabil 2005; 32: 584-588

Anxiety had a similar prevalence in bruxers and non-bruxers, but there were differences in certain panic disorder factors.

There appears to be some confusion in studies of the relationship of anxiety to bruxism, and the aim of the present study was to investigate any possible association. Subjects in an Italian prosthetic dentistry clinic who did not have temporomandibular disorders were investigated for bruxism and the presence of anxiety psychopathology symptoms.

In a sample of 98 subjects, 34 bruxers were compared with 64 nonbruxers, using a self-report questionnaire for panic-agorophobic spectrum. This questionnaire has 114 items in 7 domains: separation anxiety, panic symptoms, stress sensitivity, substance sensitivity, anxious expectation, agoraphobia, hypochondria, and reassurance sensitivity. There were no significant differences between groups in respect of anxiety psychopathology (overall scores 35+). However, the basic scores and domain scores showed differences: panic symptoms, stress sensitivity and reassurance sensitivity were significantly commoner in bruxists. The authors note that the associations they have found are not evidence of causation.

doi:10.1038/sj.bdj.4812813

\section{ENDODONTICS}

\section{Complications associated with fractured file removal using an ultrasonic technique}

Souter N, Messer HH J Endodon 2005; 31: 450-452

Perforation was a frequent complication of attempts to remove the file from the apical third of canals.

In 45 extracted molars, a $3 \mathrm{~mm}$ section of file was experimentally fractured in the mesiolingual canal. The canal was enlarged to a funnel shape to allow visualisation and an attempt to remove the instrument. Where this was successful, canals were then filled, along with those in 15 control teeth. Approximately 1/3 of instruments were fractured in the coronal third of canals, $1 / 3$ in the middle third, and $1 / 3$ in the apical. Middle and coronal third removals were successful, but only 4 of 11 were removed in the apical third. The root was significantly weakened by attempts to remove apical third fragments.

In a clinical study of 60 cases, removal was again successful in all coronal and middle thirds, but only 9 of 27 apical removals were successful, with 7 resultant perforations. Because of the hazards of root perforation and root fracture, the authors conclude that removal of fractured files should not be attempted beyond the curve of the canal.

\section{ENDODONTICS}

\section{Study of calcium hydroxide apexification in 26 young permanent incisors}

Domingues Reyes A, Muñoz L et al. Dent Traumatol 2005; 21: 141-145

Preoperative symptoms did not affect outcome, and there was no relationship between the state of the pulp and the time for apical closure.

Necrosis after trauma to permanent teeth is most frequent when apices are left open. Promotion of complete apical closure is therefore an aim of treatment. In this study, pulps were removed from 26 traumatised teeth in 19 patients aged 6-9 yrs, and after flushing with sodium hypochlorite, canals were filled with pure calcium hydroxide in distilled water.

Apical closure occurred in all cases, and 18 teeth which had had pain symptoms or fistula or radiographic signs at the first examination were symptomless after treatment. In $3 / 4$ of cases, the apical shape was physiological. The authors noted that the apical diameters progressively decreased after treatment, and suggested that the treatment was necessarily the cause of the closure. More divergent apical walls took longer to achieve closure.

doi:10.1038/sj.bdj.4812815

NEUROLOGY; MAXILLOFACIAL SURGERY

Neurosensory disturbance after sagittal split and intraoral vertical ramus osteotomy: as reported in questionnaires and patients' records

Al-bishri A, Barghash Z et al. Int J Oral Maxillofacial Surg 2005; 34: 247-251

Surgeons were more optimistic than patients in assessing sensory outcome.

Sagittal split (SSO) and vertical ramus osteotomies (VRO) have been widely used to correct mandibular deformity. This study aimed to compare neurological outcomes in 79 VRO and 50 SSO patients. One year or more after surgery, 53 VRO and 43 SSO patients returned questionnaires which were compared with the assessment of the surgeons in the patients' records.

Neurosensory disturbances (NSD) were reported in 11 operated sides where VRO had occurred, and 25 SSO sides. Respective figures for long-lasting NSD were 8 and 10 sides. Post-operative surgical assessments, however, indicated respectively 4 and 7 sides with long-lasting NSD. The authors note that some operators consider patients' subjective assessments to be less reliable than objective evaluation, but consider the patients' assessment of outcome to be more important.

doi:10.1038/sj.bdj.4812815 